

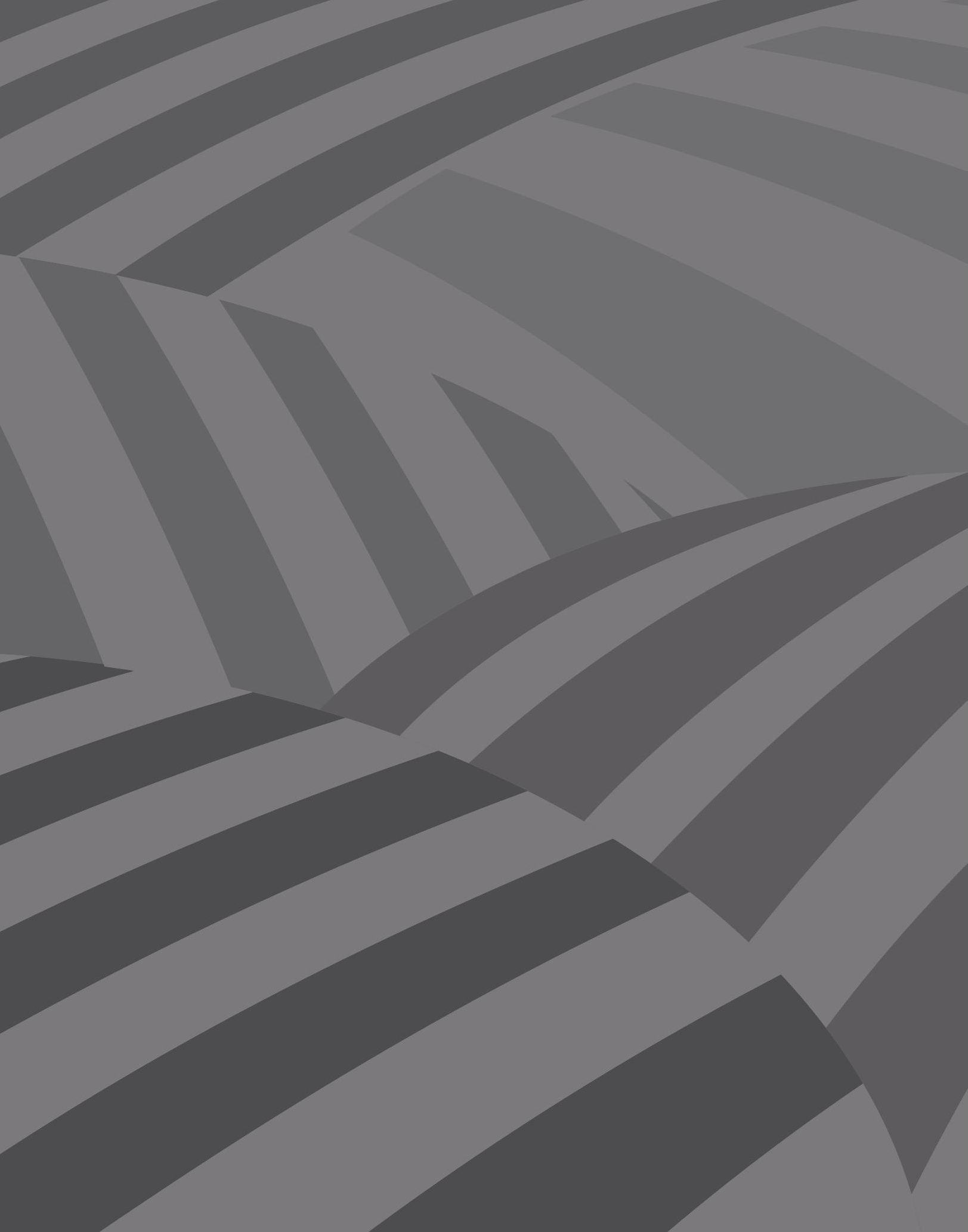




\section{Buscando los rostros campesinos de por acá. Una aproximación desde la noción de vida campesina*}

Por Silvia Juliana Becerra Ostos** y Julieth Rojas Guzmán***

$\mathrm{E}$ ste trabajo es una revisión de las perspectivas predominantes de análisis que sobre lo campesino se han desarrollado en el país. Proponemos un enfoque analítico novedoso que interrogue lo respectivo a las formas de representar, saber, hacer y significar del campesinado, a partir del concepto de vida campesina. Para ello, nos aproximamos a la construcción del concepto de vida campesina, desde un enfoque intercultural que interroga las prácticas y significados de las comunidades rurales en la cotidianidad. Hacemos también referencia a diversos análisis desde la dimensión productiva, destacándola como una de las perspectivas predominantes que han contribuido a caracterizar al campesinado, así como lo han hecho los estudios en relación a fenómenos sociales - reforma agraria, colonización, narcotráfico, despojo, desplazamiento y desterritorialización, entre otros-. Por último, ponemos en discusión el enfoque multicultural - teniendo en cuenta los matices que lo revisten desde la Constitución de 1991—, el cual ha resultado problemático en la medida en que ha generado barreras entre las distintas poblaciones que conforman la nación colombiana. Estas fronteras, definidas cada vez más con el paso de los años, han generado conflictos entre las comunidades que comparten y construyen

* $\quad$ Artículo recibido en agosto de 2015

Artículo aprobado en octubre de 2015

* Politóloga. Magister en Historia de la Universidad Nacional de Colombia y docente de la misma institución y de la Universidad Pedagógica Nacional.

*** Antropóloga de la Universidad Nacional de Colombia. 
territorios comunes. Las problemáticas a las que hacemos alusión están ligadas a la tenencia, uso y forma de gobernar un territorio bajo políticas públicas que responden a un enfoque multiculturalista y que por esta característica se convierten en una barrera para la construcción de horizontes posibles desde lo común.

Sumado a lo anterior, evidenciamos la escasa producción de trabajos investigativos sistemáticos de carácter etnográfico sobre sociedades campesinas en el país, por lo que consideramos la necesidad de indagar sobre las relaciones entre campesinado y cultura. Con esto pretendemos ampliar la comprensión de las multiplicidades y complejidades del sujeto campesino, a la vez que deseamos hacer un aporte a la disminución de la brecha de conocimiento al respecto, existente tanto en la academia como en el Estado colombiano.

\section{Interculturalidad y vida campesina}

El concepto vida campesina parte de la indagación sobre los elementos que configuran culturalmente lo campesino, y con él se pretende problematizar la perspectiva multicultural y el concepto mismo de cultura para ponerlo en diálogo con dimensiones políticas, ambientales y productivas, que también son culturales. Desde esta perspectiva se reconoce que lo económico implica, entonces, una serie de reformas que están involucradas en el modo de relacionarse de las comunidades rurales en el país y que hablan de manera intrínseca de una configuración cultural —en el hacer, el pensar, el sentir, el representar-. El hecho de cultivar refleja un proceso previo de socialización y de aprendizajes de elementos socioculturales que permiten construir una relación con el entorno y emplear técnicas pertinentes para contextos específicos, es decir, conocimientos concretos y situados. Estos conocimientos están ligados a la diversidad poblacional y productiva del campesinado colombiano, y se expresan a través de las relaciones en torno al agua, el monte, la sierra y demás lugares que permiten significar y construir vínculos que se manifiestan en prácticas culturales. Entre las más relevantes de estas prácticas están las 
relaciones vecinales, el compadrazgo, el uso y regulación de los recursos naturales — la pesca, la minería, la producción artesanal—. La visión tradicional según la cual el campesino es aquel que tiene tierra y está ligado a la producción agraria excluye de sus categorías de análisis estos saberes y formas de hacer, mientras que la noción de vida campesina permite ampliar el horizonte de indagación sobre la multiplicidad de los sujetos campesinos.

Armando Bartra (2010) define al campesinado como un modo de vida, donde la diversidad es un elemento constitutivo fundamental tanto en las actividades productivas, como en las "escalas de inserción en el sistema mayor, de sociabilidad, de cultura” (p.10). En términos sociales, este autor define al campesinado como una colectividad, un conglomerado social cuya base es la economía familiar multiactiva y la construcción de relaciones y redes de protección de base comunitaria; es decir, propone un análisis de estrategias solidarias de sobrevivencia que, en muchas ocasiones, suplen la institucionalidad. Bartra plantea, además, que en términos económicos es campesino quien siembra a pequeña o mediana escala, aunque se trate de una actividad permanente o temporal. Pero, asimismo, señala que también lo es el jornalero, el productor especializado, quien vive de la pesca, del bosque y, por último, quien trabaja en lo pecuario, en la fabricación de artesanías o herramientas para las labores domésticas y del trabajo.

Esta pluralidad responde, primero, a las muchas maneras de relacionarse con la naturaleza ecodiversa, lo que se expresa "en multiplicidad de patrones tecnológicos, productivos, societarios y simbólicos” (Bartra, 2010, p.11); y segundo, conforme a los postulados del mismo autor, la pluralidad campesina se evidencia en las formas en las que las poblaciones rurales se insertan "en el sistema mayor, de las que resulta un polimorfismo socioeconómico extremo que va del trabajo asalariado al autoconsumo, pasando por la agricultura comercial ocasionalmente asociativa” (p.11). 
Para rastrear y comprender esta diversidad es necesario identificar lo que ha conformado a las comunidades campesinas colombianas, ya que la cultura, como advierte Alejandro Grimson (2011), es un elemento que se estructura históricamente y no es determinado a priori. Por ello, las investigaciones de carácter etnográfico rastrean prácticas sedimentadas a partir de un abordaje desde la cotidianidad e integran en el análisis la heterogeneidad, las disputas, desigualdades y conflictos. Grimson también aclara que toda configuración cultural habla de un marco compartido por actores diversos que se articulan en la complejidad de la heterogeneidad social; esta complejidad se caracteriza por cuatro elementos fundamentales: campos de posibilidad, lógicas de interrelaciones, tramas simbólicas comunes y aspectos culturales compartidos:

No sólo aparecen rasgos diferenciadores sino que hay un régimen de articulación de dichos rasgos. Pensar en términos de configuración no significa homogeneidad (que todos los participantes de una cultura lo hagan de la misma manera) y aceptación (que sea aceptada por todos y en los mismos términos), sino que establece los términos y el terreno de las heterogeneidades y de los rechazos. Cuando se piensa en la configuración se hace énfasis en prácticas sedimentadas en entramados de relaciones de poder hechas espacialidades, corporalidades, subjetividades, legibilidades e inteligibilidades (Restrepo, 2012, p.39).

En este sentido, las nociones de vida campesina y configuración cultural proponen nuevas miradas para abordar las relaciones entre campesinado y cultura, así como también proponen contribuir a la ruptura de la dicotomía tradicional entre ciudad y campo. Esto es fundamental para asumir lo local y lo regional no como escalas geográficas diferenciadas, sino como diversos ámbitos en los que el sujeto campesino se mueve. Es decir, un enfoque multiescalar permite indagar a profundidad sobre el sistema urbano-rural-regional y develar realidades que reflejan la diversidad en las formas de articulación de las ciudades, sus entornos rurales y las maneras como funcionan los grupos sociales; nos referimos con esto las adaptaciones urbanas y las formas de trabajo y de reproducción 
social actuales de las comunidades rurales. Indagar acerca de los procesos sociales e históricos de configuración de las vidas campesinas contribuye a la transformación de la valoración social, cultural, política y económica del campesinado en el país, en la medida en que se apuesta por una comprensión de su quehacer cotidiano y, desde allí, de su aporte a la formación social colombiana.

\section{El campesino y la producción}

Bajo la premisa que define al campesino como aquel que tiene tierra y está ligado a la producción agraria se han adelantado de manera sistemática investigaciones que describen la relación entre algunas características de tipo productivo y el territorio. En estas se manifiesta que las formas de producción encaminadas a garantizar la subsistencia, total o parcial, a través de la fuerza de trabajo propia o familiar, se consideran formas de producción campesinas, incluso cuando se contrata a trabajadores asalariados como mano de obra subsidiaria ${ }^{1}$.

El campesino organiza sus formas de trabajo de manera que le permitan el máximo rendimiento con un mínimo costo de capital. Son, pues, la tecnología simple y el uso extensivo del trabajo familiar los medios para lograr un equilibrio entre ambas. De tal suerte, como señala Krantz (1977) son las necesidades de subsistencia de la familia lo que guía la empresa campesina y no la compensación del trabajo familiar con un salario promedio; el campesino se enfrenta entonces a dos relaciones diferentes con los medios de producción y con el sistema capitalista que se constituyen

Véase: Chayanov, A. V. (1986). "Sobre la teoría de los sistemas económicos no capitalistas”. En J. Aricó, Chayanov y la teoría económica campesina. Bogotá: Siglo XXI Editores. 49-83; Krantz, L. (1977). "El campesinado como concepto analítico”. En Nueva antropología-Revista de Ciencias Sociales, 87-98; Toledo, V. (1992). "La racionalidad ecológica de la producción campesina” en E. Sevilla y M. González de Molina (Eds.) Ecología, campesinado e historia. Madrid, España: La Piqueta; Vélez Vargas, L. D. (2015). Adaptabilidad y persistencia de las formas de producción campesina. Bogotá: Universidad Nacional. 
mutuamente. Por un lado, se establecen relaciones de producción para la subsistencia, y, por el otro, se produce una superganancia para el capital que, a su vez, genera un constante déficit para el campesino.

En este sentido, se produce una crisis semipermanente del agro, la cual, según cifras de 2015 de la Organización para la Cooperación y el Desarrollo Económico — OCDE-, se evidenció en la reducción del 2\% del área sembrada en el país en un periodo de veinte años —de 1990 a 2010 - y en el descenso de la importancia del empleo en el sector agropecuario, que pasó del 26\% en 1990 al 17,5\% en 2013. Esta crisis también se ha evidenciado en el crecimiento de la importación de alimentos, la cual, según el Sistema de Agricultores Colombiano —SACha registrado lo siguiente para 2016:

[1] as importaciones asociadas al sector no paran de crecer, entre enero y septiembre de 2015, se importaron 8,8 millones de toneladas de alimentos y materias primas agropecuarias por valor de US\$ 4451 millones, cifras que, comparadas con igual periodo de 2014, reflejan un aumento de 9,3\% en volumen y un descenso de $6,3 \%$.

Sin embargo, al complementar esta lectura con la información sobre desnutrición, que entidades como el ICBF y la FAO han proporcionado, observamos que el problema no es de producción de alimentos, sino de falta de acceso a ellos; problemática compartida por la ciudad y el campo.

Estas discusiones sobre las formas de producción campesina y la superganancia que genera el campesinado para el mercado, las urbes y las grandes industrias; así como el papel de intermediación que juegan los poderes locales, no estarían completas sin comprender la distribución, uso y tenencia de la tierra en el país y la construcción de territorialidades campesinas. Según el Programa de las Naciones Unidas para el Desarrollo, el DANE plantea que más del 70\% de los municipios de Colombia son rurales, es decir, aproximadamente el $90 \%$ del país, lo que 
refleja la dimensión de los análisis adelantados y de la importancia de profundizar en la comprensión de las comunidades campesinas y sus relaciones culturales, dentro de lo cual se encuentran los procesos de construcción de territorialidades.

Según esta perspectiva, el campesinado se define como tal en la medida en que tiene un papel en la cadena productiva y aporta su mano de obra, pero, asimismo, no son reconocidas sus capacidades en términos de ser dueño de su fuerza de trabajo y tener una forma de relación particular con el resto de la naturaleza. Este acercamiento ha implicado un cambio de enfoque en la comprensión y uso de lo rural expresado en la reprimarización de la economía, sobre todo en contextos marcados por una economía de guerra. Esto nos pone en la perspectiva de analizar también la relación que ha construido el campesinado con el Estado.

El Estado ha empleado diversas formas de articulación e integración con los campesinos, pero también ha promovido prácticas de desvaloración de su papel: ha reconocido y concedido escasos derechos en términos de titularidad sobre activos, derechos laborales y reconocimiento social y político, principalmente en la primera mitad del siglo XX y en el proceso de constitución de la Asociación Nacional de Usuarios Campesinos (ANUC). Estas relaciones se han roto no solo por la debilidad que las constituye, sino, en términos de Salgado (2010), porque en la actualidad los campesinos tienden a emplearse como mano de obra para inversionistas y empresarios agrarios y no como productores independientes. La tenencia de la tierra, como factor de producción, ha sido una de las problemáticas en las que se han concentrado muchos análisis sobre lo campesino, y en ese sentido se han adelantado las luchas y demandas del sector. Si bien no se ha superado el problema de la tenencia, las demandas y discursos políticos de las organizaciones campesinas se han complementado con discusiones en torno a la transferencia tecnológica, la asistencia técnica, la posibilidad de comercialización, la participación política y el reconocimiento del campesinado como sujeto político y de derechos. 
Estas discusiones cobran cada vez más importancia porque, entre otros factores, en la última década la agricultura muestra cierto dinamismo en relación con la mayor parte del siglo XX, cuando el crecimiento industrial fue el abanderado de la economía nacional. Este dinamismo se explica principalmente por una decidida y sistemática apuesta de las políticas agrarias en favor de la modernización y la competitividad de la agricultura comercial y los cultivos de rendimiento tardío. También se ha visto favorecido por una mayor demanda mundial de bienes primarios, por la consecuente presión al alza de los precios de estos productos y el mejoramiento de las tasas de cambio real en favor de las agroexportaciones. Este panorama pone nuevamente en el debate nacional la vieja pregunta sobre el papel del campesino dentro del modelo de desarrollo económico y social.

La discusión sobre la productividad, es decir, sobre el modelo de desarrollo económico y social, no puede dejar por fuera la pregunta por el modelo de ordenamiento territorial. En el caso de las sociedades campesinas este ordenamiento se basa en un ejercicio práctico, comunitario y cotidiano, cuyo núcleo fundamental, en muchos lugares de Colombia, es la vereda. En este ejercicio uno de los elementos convocantes ha sido la lucha por la tierra y la construcción del territorio con otros rurales, con quienes el campesinado ha construido históricamente su lugar en el mundo. Ahora bien, la tierra no se interpreta en la actualidad como un simple factor de producción. De hecho, algunos autores desde 1970 advertían la necesidad de estudiar lo agrario como "un sistema de interrelaciones económicas, sociales, culturales y políticas cuyo núcleo central está constituido por la propiedad sobre la tierra y sobre los recursos para utilizarla, de acuerdo con patrones históricos de economía y de organización social” (García, 1973, p.117).

\section{Multiculturalismo: fronteras, reconocimiento y redistribución}

A partir de la constitución política de 1991 la diversidad en Colombia ha sido abordada desde un enfoque multicultural que entiende la coe- 
xistencia de grupos culturales diferentes dentro de una misma nación; grupos considerados en general como minorías al interior de un Estado democrático. Esta perspectiva ha permitido abandonar la idea de que las naciones son un todo homogéneo y monocultural, y ha marcado la urgencia de promulgar derechos diferenciales con el fin de que se reconozca y proteja la diversidad y se procure equidad social y no discriminación. Sin embargo, en Colombia este enfoque se ha concretado también en la agudización de conflictos entre poblaciones que conviven separadas por fronteras que parecen producirse históricamente ${ }^{2}$.

Tal como lo propone Alicia Barabás (2014), "las experiencias concretas del multiculturalismo ligado con la globalización, que se funda en la idea de sumatoria de diversidades o mosaico cultural, ha producido segregación entre culturas, marginación y constitución de ghettos” (p.3). Esto trae como consecuencia la baja correspondencia entre las necesidades de la población campesina y las políticas públicas, formuladas a partir de las premisas de comunidades estáticas y límites culturales entre las poblaciones $^{3}$. Por lo anterior, las organizaciones campesinas demandan legítimamente su reconocimiento colectivo a partir de una identidad cultural, lo que evidencia la necesidad de generar reflexiones al respecto que trasciendan lo discursivo.

2 Barth, F. (1976) en Los grupos étnicos y sus fronteras. La organización social de las diferencias dice que las fronteras étnicas son conservadas en cada caso por un conjunto de rasgos culturales. Por tanto, la persistencia de la unidad dependerá de la persistencia de estas diferencias culturales, y su continuidad puede ser especificada por los cambios en la unidad producidos por cambios en las diferencias culturales que definen sus límites.

3 DNP. (2015). El campo colombiano: un camino hacia el bienestar y la paz. Bogotá; LeGrand, C. (Enero-Abril de 1984). De las tierras públicas a las propiedades privadas: acaparamiento de tierras y conflictos agrarios en Colombia. Lecturas de Economía (13); Machado Cartagena, A. Políticas agrarias en Colombia 19001960. 1986, Bogotá: Centro de Investigaciones para el Desarrollo; Congreso de la República de Colombia Ley 0200, 1936; Ley 100 de 1944; Plan Nacional de Desarrollo 2014-2018; PNUD. (2011). Razones para la esperanza. Bogotá. 
Encontramos que la pregunta por las relaciones culturales que permitan comprender lo campesino ha sido abordada desde la construcción identitaria que surge en respuesta a las políticas estatales, así como frente a las necesidades y búsquedas propias del campesinado, toda vez que expresan intereses y necesidades comunes. Desde tal perspectiva se enfatiza en que el Estado ha construido políticamente una identidad campesina. Por un lado, la diferencia y la diversidad se plantean como productos de la interacción social y, por el otro, como campos de dominación en tanto que la política estatal enuncia y produce como culturas a los grupos que expone frecuentemente a sus ejercicios de poder. Desde esta perspectiva "la cultura es producida políticamente y se sabe que la política es también un proceso de construcción de significados; esto es, un proceso cultural” (Bolívar, 2006, p. 4).

La construcción de identidades, la definición de un hecho o comportamiento como cultural y la formación del Estado son procesos profundamente ligados y resultado de una intensa lucha política. Esta lucha, según Ingrid Bolívar (2006), se realiza basada en una interdependencia social que hace que la pertenencia a un grupo más o menos definido garantice protección, respaldo y acceso a ciertas condiciones para la vida. Así pues, la identidad está conectada a la agencia y a la construcción de una estrategia del juego político, el cual tiene que ver con los imaginarios creados desde el Estado, la sociedad, y los individuos, y que impacta la formación de identidades tanto individuales como colectivas. Estas perspectivas hablan sobre los campesinos de modo estereotipado como "atrasados" e "ignorantes", con formas de producción "poco rentables” y "obsoletas” que, como señala Forero (2010), se convierten en un obstáculo para el desarrollo.

En las organizaciones campesinas y los movimientos sociales en general es posible identificar la preocupación por ligar los asuntos culturales a la pregunta por lo campesino. Ellos han elaborado propuestas en las cuales enfatizan la importancia de garantizar el desarrollo y conservación de sus culturas. Aun así, existen múltiples dificultades para conceptualizar 
y definir sus prácticas, saberes, sentidos, significados, concepciones y creencias. Es por ello que diversas lecturas y análisis se acercan a los elementos que constituyen el campesinado con el objetivo de aportar en el conocimiento profundo y la descripción del mismo. Encontramos así estudios que afirman que el campesinado es entendido como el resultado histórico concreto de diferentes procesos sociales, productivos y políticos, frente a los que se distinguen ciertos rasgos característicos ${ }^{4}$. Entre los más relevantes están: construcción de identidades múltiples, un mayor acervo de capacidades para enfrentar formas de producción nuevas y cambiantes, trabajo y poder; es decir, una "permanente evolución histórica y capacidad de adaptación y resistencia” (Planeta Paz, 2002, p. 14).

Se resalta la diversidad como constitutiva del campesinado y se señala que en ella subyacen las claves históricas de la gran capacidad que tiene para resistir y adaptarse a nuevos roles, para interlocutar y coexistir aún en medios y condiciones tan difíciles y hostiles como las que hoy le imponen el modelo de desarrollo neoliberal y el conflicto armado colombiano. En esta misma perspectiva, la demanda central de los campesinos para el resto de la sociedad y el Estado es que se reconozca su condición de sujetos de derechos; lo cual es deducible de del actual debate por la

4 Ver Bolívar R., I. (2006). Identidades Culturales y Formación del Estado en Colombia. Bogotá: Ed. Universidad de los Andes; Forero Álvarez, J. (2010). El campesino colombiano entre el protagonismo económico y el desconocimiento de la sociedad. Bogotá: Pontificia Universidad Javeriana; Matijasevic, M. T., \& Ruíz, A. (2012). “Teorías del Reconocimiento en la comprensión de la problemática de los campesinos y las campesinas en Colombia”. En Revista Colombiana de Sociología, 35(2), 111-137; Planeta Paz. (2002). Documentos de caracterización sectorial. Sector Campesinado. Bogotá; Planeta Paz. (2012). Ciclo de conversatorios. La cuestión agraria en Colombia. Bogotá: 2012; Quesada, C. (2013). Derecho a la Consulta Previa para comunidades campesinas. Tesis para optar al título de Magíster en Derecho. Universidad Nacional de Colombia. Bogotá; Velasco, M. (2014). Quiénes son hoy los/as campesinos/as: un acercamiento al proceso de construcción de identidad campesina en el marco del conflicto armado en Colombia. Tesis para optar al título de Maestría en Ciencias Sociales con mención en Sociología. Quito, Ecuador: Facultad Latinoamericana de Ciencias Sociales, Flacso. 
ratificación de los derechos campesinos en la ONU, de las discusiones en las Mesas de Interlocución y Acuerdos, MIA, y de eventos regionales campesinos - como es el caso del foro sobre derechos integrales del campesinado realizado en noviembre de 2015 en Popayán-.

Las demandas de las organizaciones campesinas por su reconocimiento como sujetos políticos y de derechos no son excluyentes de las demandas por la redistribución de la tierra, sino complementarias en la superación de injusticias socioeconómicas y culturales. La idea de que el campesinado busca ser aceptado y reconocido es fundamental en este enfoque, ya que como señala Forero (2010), el desconocimiento social del problema de la tierra y de la producción se debe en tal medida a su falta de reconocimiento como sujetos políticos ${ }^{5}$. Esta falta de reconocimiento responde a la manera como el Estado ha caracterizado a las poblaciones campesinas, lo cual puede evidenciarse en el manejo del mercado de tierras y en algunas leyes formuladas y ejecutadas a favor de las clases dominantes, hecho advertido por muchos investigadores ${ }^{6}$. Tal situación ha implicado que el campesino esté desligado de escenarios decisivos y que su accionar esté limitado por el paternalismo estatal. Así, los movimientos campesinos buscan, en términos de Velasco (2014), inclusión y representación política que redunde en el reconocimiento y redistribución justa y equitativa de los recursos, así como la garantía de sus derechos políticos, sociales, económicos y culturales. Sin embargo, el abordaje identitario en la contemporaneidad parece desbordarse y muchas veces dificulta el reconocimiento y la reelaboración de

5 Vale la pena anotar, que en este tipo de acercamientos, las organizaciones campesinas son los sujetos centrales de análisis, muchas veces incorporadas en una alusión general de los campesinos como actor.

6 LeGrand, C. (Enero-Abril de 1984). De las tierras públicas a las propiedades privadas: acaparamiento de tierras y conflictos agrarios en Colombia. Lecturas de Economía (13); Machado Cartagena, A. Políticas agrarias en Colombia 19001960. 1986, Bogotá: Centro de Investigaciones para el Desarrollo; Congreso de la República de Colombia Ley 0200, 1936; Ley 100 de 1944; Plan Nacional de Desarrollo 2014-2018; PNUD. (2011). Razones para la esperanza. Bogotá. 
relaciones interétnicas e interculturales que son fundamentales para la vida colectiva en el país. Este es un problema que no solo alude a un territorio en específico, sino es un asunto de ámbito nacional; es por ello que se hace necesario enfatizar que las reivindicaciones de orden cultural no son exclusivamente de carácter étnico.

En este sentido, Carlos Quesada (2013) se aproxima al campesinado como cultura, entendida como un sistema social de producción, puesto que la economía campesina implica una forma de producir distinta a la capitalista y constituye a su vez un modo de producir la vida. Este modo está caracterizado por las formas en las que el campesinado se relaciona con el ambiente, lo cual conlleva una "rica producción de conocimientos que han permitido la sostenibilidad de este modo de producir por más de 10.000 años” (p.46).

La cultura es, en la contemporaneidad, un campo muy importante de participación social, cuyos avances pueden ser identificados en el ámbito de los derechos diferenciales de carácter étnico. En este sentido, el abordaje sobre los aspectos culturales que hemos mencionado se propone desde el concepto de vida campesina, entendiendo la cultura como quehacer cotidiano; de este modo es posible preguntarnos por la relación entre poblaciones rurales. Es decir, el reto es encontrar elementos comunes entre comunidades rurales que hoy se excluyen entre sí como resultado de la perspectiva multicultarista, pero que a la vez se encuentran totalmente marginadas.

Esta preocupación por las relaciones interculturales permite el retorno al problema de la desigualdad, abordada principalmente por el marxismo, desde el análisis de las relaciones de producción. Pero es necesario, según la lógica que venimos exponiendo, complementar el análisis con elementos culturales de dicha producción y reproducción. Claro está, sin negar los elementos étnicos ni subsumirlos, sino, más bien, recordando que nuestra región en el marco de la implementación constitucional del multiculturalismo (1980-1990) fue la de mayor disparidad 
de ingresos y el Gini más alto de desigualdad ${ }^{7}$. Es a esto que se refiere Raygadas (2007) cuando dice que en este periodo se universalizó el derecho a la diferencia como un elemento positivo, pero se negaron los derechos económicos y sociales.

\section{Una perspectiva en construcción: buscando los rostros de la vida campesina}

Como hemos señalado, la reflexión en torno a las relaciones de producción fue una de las perspectivas analíticas propias del siglo XX $\mathrm{y}$, además, una desde la que el campesinado fue configurado. En su configuración, se hicieron evidentes una serie de relaciones de carácter productivo en donde las consideraciones de tipo sociocultural y socioambiental fueron insuficientes para posicionar al campesinado más allá de la producción de alimento $^{8}$. Esta visión contribuyó a afianzar una relación funcional de la sociedad con el conjunto de esa población, sin un reconocimiento mediado por el valor sociocultural que esta pudiera tener para la nación colombiana.

Caracterizar y comprender a las comunidades campesinas del país es un reto que implica dejar de pensar en dicotomías, en sociedades estáticas, homogéneas y aisladas, para realizar un acercamiento que incluya la complejidad, diversidad y versatilidad de estas poblaciones, así como los conflictos, disputas y divergencias que las constituyen. Estos esfuerzos

El Gini —o Coeficiente Gini- es una medida de desigualdad que normalmente se utiliza para medir la inequidad en los ingresos dentro de un país, pero puede utilizarse para medir cualquier forma de distribución desigual.

8 Ver: Chayanov, A. V. (1986). "Sobre la teoría de los sistemas económicos no capitalistas”. En J. Aricó, Chayanov y la teoría económica campesina. Bogotá: Siglo XXI Editores; Krantz, L. (1977). “El campesinado como concepto analítico”. En Nueva antropología. Revista de Ciencias Sociales, 87-98; Kroeber, A. (1945). Antropología general. México: Fondo de cultura económica; Reyes, A. (1978). Latifundio y poder político: la hacienda ganadera en Sucre. Bogota: CINEP; Shanin, T. (1971). Campesinos y sociedades campesinas. México D.F.: Fondo de Cultura Económica.; Wolf, E. (1971). Los campesinos. Barcelona: Editorial Labor. 
por la comprensión del campesinado son necesarios para aportar en el reconocimiento de este conglomerado social, pues como ha propuesto Forero (2010), esta falta de reconocimiento por parte del Estado, la sociedad y los individuos impacta en la formación de identidades, la redistribución equitativa de los recursos y los beneficios a los que tienen derecho ciertos sectores sociales. Es decir, las comunidades campesinas son bivalentes, como propone Nancy Fraser, -citada por Matijasevic y Ruíz (2012). en tanto son sujetos de injusticias socioeconómicas y culturales, que plantean el problema de atender simultáneamente dos demandas aparentemente contradictorias: “de redistribución — centradas en la igualdad - y de reconocimiento — centradas en la diferencia-” (Matijasevic yRuíz, 2012, p.123).

En ese mismo sentido, Taylor, citada por Matijasevic y Ruíz (2012), enuncia que la relación entre reconocimiento e identidad —la cual está en parte formada por la presencia o la ausencia de reconocimiento- se convierte en un instrumento de opresión. Para esto plantea el concepto de Misrecognition o mal reconocimiento, ya que se encuentra en juego la imposición de una imagen negativa de sí a un sujeto, sea este individual o colectivo (). En esta misma dirección, Axel Honnet - en el libro de Matijasevic y Ruiz (2012) -plantea que es necesario entender el reconocimiento también desde las prácticas y regulaciones institucionales, un lugar donde el campesinado colombiano está siendo invisibilizado sistemáticamente a partir de diferentes políticas y el uso de categorías tan amplias como la de productor.

Por lo tanto, consideramos que el concepto vida campesina contribuye a reconocer lo campesino tanto desde sus particularidades como desde su capacidad de evidenciar una trama social de mayor amplitud. Estas dos características son vitales para abordar la relación con los otros rurales, la cual no ha implicado, ni implica en el presente, un carácter conflictivo entre indígenas, poblaciones afro y campesinas. En tal medida, es importante indagar sobre las experiencias de vida intercultural e interétnica como parte constitutiva de lo campesino. No se trata 
entonces de eliminar el concepto de cultura ni el de reconocimiento, ni los derechos diferenciales que algunas comunidades han ganado legítimamente; tampoco se trata de negar los derechos culturales y la diversidad, o de desandar el camino recorrido que pone de manifiesto la importancia de lo simbólico. Se trata, como defiende Raygadas (2007), de refutar el fundamentalismo y el conservadurismo asociados a muchas de sus formulaciones y de replantear la perspectiva con la que se ha intentado caracterizar y comprender la diferencia y la diversidad en el país, esto con el objetivo de reconocer las heterogeneidades, convergencias, disputas y los mecanismos de interacción entre poblaciones diversas. Como apunta Barabás (2014),

con la adquisición de competencia cultural sobre el Otro se posibilita la interculturalidad y se destruyen los estereotipos y prejuicios negativos que suelen ser producto de la ausencia o mala calidad de la información acerca de los estilos de vida de los otros culturales con los que se convive ( p. 16).

Por ello, emprender este tipo de investigaciones implica plantear algunas cuestiones fundamentales alrededor de la pregunta sobre cómo se desenvuelven las vidas campesinas en la actualidad, pues, en palabras de Raygadas (2007), "es fundamental que se hagan investigaciones que vinculen las descripciones culturales densas con procesos económicos y culturales” (p. 357). Solo de este modo sería posible responder cuáles son las principales dinámicas de producción que les permite a los campesinos insertarse a los sistemas agroalimentarios regionales; cómo se organiza la vida social de los campesinos en las prácticas cotidianas; cuáles son las relaciones que se construyen con los diferentes ámbitos del poder político y administrativo en las escalas local, regional y nacional, y, por último, cuáles son los usos y prácticas en relación con el territorio.

Estas preguntas podrían ser abordadas en el contexto dentro del cual se han constituido las vidas campesinas a partir de su transformación y constitución histórica, considerando el cerramiento de la frontera 
agropecuaria, los procesos de despojo histórico, los conflictos armados, así como los costos que la guerra ha generado sobre la reproducción cultural del campesinado en el país. Asumir esta indagación busca replantear algunos de los lugares comunes desde los que el sujeto campesino ha sido caracterizado, así como también responder de manera mucho más contundente y eficaz los cuestionamientos ya planteados. Esto se debe a que no solamente se deben hacer aproximaciones desde los conceptos sino también desde la construcción de un camino para avanzar en el reconocimiento amplio y comprensivo de todas las poblaciones, de todos los sujetos que componen la nación colombiana y contribuir a la proyección de políticas públicas que respondan a la complejidad de las vidas campesinas en el país.

\section{Bibliografía}

Barabás, A. M. (2014). Multiculturalismo, pluralismo cultural y interculturalidad en el contexto de América Latina: la presencia de los pueblos originarios. En Configurações, 11-24.

Barón, O. (2015). Saberes campesinos: las comunidades ASOPRICOR y su vida en el Alto Magdalena y el Tequendama. Tesis de pregrado para optar al título de Antropólogo. Bogotá: Universidad Externado.

Barth, F. (1976). Los grupos étnicos y sus fronteras. La organización social de las diferencias. México D.F.: Fondo de Cultura Económica.

Bartra, A. (2010). Campesindios. Aproximaciones a los campesinos de un continente colonizado. En Revista Memoria, 4,.4-13.

Becerra OSTOS, S. (2005). Convicción, esperanza y trabajo. Las comunidades campesinas en resistencia. El caso de la ACVC. Tesis de pregrado para optar al título de Politóloga. Bogotá: Universidad Nacional de Colombia.

Bolívar R., I. (. (2006). Identidades Culturales y Formación del Estado en Colombia. Bogotá: Editorial Universidad de los Andes.

Castro, D. (2011). Campesinos recolectores y productores de guayaba de Puente Nacional: cambios y permanencias. Tesis de pregrado para optar al título de Antropólogo. Bogotá: Universidad Externado. 
Centro Nacional de Memoria Histórica. (2014). La tierra en disputa: Memorias de despojo y resistencia campesina en la Costa Caribe 1960-2010. Bogotá: $\mathrm{CNMH}$.

Chayanov, A. V. (1986). Sobre la teoría de los sistemas económicos no capitalistas. En J.Aricó (Ed.) Chayanov y la teoría económica campesina (pp.4983) Bogotá: Siglo XXI editores.

Congreso de la República de Colombia. (1936). Ley 0200.

Congreso de la República de Colombia. (1944). Ley 100.

Congreso de la República de Colombia. (2011). Ley 1448.

Congreso de la República de Colombia. (2014). Plan Nacional de Desarrollo 2014-2018.

Díaz Callejas, A. (2002). Colombia, la reforma agraria, sus documentos fundamentales. Cartagena: Universidad de Cartagena.

DNP. (2015). El campo colombiano: un camino hacia el bienestar y la paz. Bogotá.

Fajardo, D. (2002). Para sembrar la paz hay que aflojar la tierra. Bogotá: IDEA/ Universidad Nacional de Colombia.

Figueroa, J. (2009). Realismo mágico, vallenato y violencia política en El Caribe Colombiano. Bogotá: ICANH.

Forero Álvarez, J. (2010). El campesino colombiano entre el protagonismo económico y el desconocimiento de la sociedad. Bogotá: Pontificia Universidad Javeriana.

Grimson, A. (2011). Los límites de la cultura. Crítica de las teorías de la identidad. Buenos Aires: Siglo XXI.

Krantz, L. (1977). El campesinado como concepto analítico. En Nueva antropología. Revista de Ciencias Sociales, (6), 87-98.

Kroeber, A. (1945). Antropología general. México D.F.: Fondo de Cultura Económica.

Legrand, C. (1984). De las tierras públicas a las propiedades privadas: acaparamiento de tierras y conflictos agrarios en Colombia. En Lecturas de Economía (13). 
Machado Cartagena, A. (1986). Políticas agrarias en Colombia 1900-1960. Bogotá: Centro de Investigaciones para el Desarrollo.

. (2009). Ensayos para la historia de la política de tierras en Colombia. De la colonia a la creación del Frente Nacional. Bogotá: Universidad Nacional de Colombia.

Matijasevic, M. T., y Ruíz, A. (2012). Teorías del Reconocimiento en la comprensión de la problemática de los campesinos y las campesinas en Colombia. En Revista Colombiana de Sociología, 35(2), 111-137.

OCDE. (2015). Revisión de la OCDE de las Políticas Agrícolas: Colombia 2015. Evaluación y Recomendaciones de Política. Obtenido de $\mathrm{Mi}$ nisterio de Agricultura: https://www.minagricultura.gov.co/Reportes/OECD_Review_Agriculture_Colombia_2015_Spanish_Summary.pdf

Planeta Paz. (2002). Documentos de caracterización sectorial. Sector Campesinado, Bogotá. 2002. Bogotá.

. (2012). Ciclo de conversatorios. La cuestión agraria en Colombia. Bogotá. PNUD. (2011). Razones para la esperanza. Bogotá.

Quesada, C. (2013). Derecho a la Consulta Previa para comunidades campesinas. Tesis para optar al título de Magíster en Derecho. Bogotá: Universidad Nacional de Colombia.

Raygadas, L. (2007). La desigualdad después del (multi)culturalismo. En Giglia, A., ¿A dónde va la antropología? (pp. 341-364). México: UAM-Iztapalapa.

Restrepo, E. (2012). Intervenciones en teoría cultural. Popayán: Universidad del Cauca.

Reyes, A. (1978). Latifundio y poder político: la hacienda ganadera en Sucre. Bogotá: CINEP.

SAC. (20 de Mayo de 2016). Sociedad de Agricultores de Colombia. Obtenido de http://www.sac.org.co/es/estudios-economicos/balance-sector-agropecuario- colombiano/290-balance-y-perspectivas-del-sector-agropecuario-2012-2013.html

Shanin, T. (1971). Campesinos y sociedades campesinas. México D.F.: Fondo de Cultura Económica. 
Tocancipá-Falla, J. (2005). El Retorno de lo campesino: Una revisión sobre los esencialismos y heterogeneidades en la antropología. En Revista Colombiana de Antropología (41)

Toledo, V. (1992)."La racionalidad ecológica de la producción campesina” en E. Sevilla y M. González de Molina (Eds.) Ecología, campesinado e historia. Madrid, España: La Piqueta.

Velasco, M. (2014). Quiénes son hoy los/as campesinos/as: un acercamiento al proceso de construcción de identidad campesina en el marco del conflicto armado en Colombia. Tesis para optar al título de Magíster en Ciencias Sociales con mención en Sociología. Quito: Facultad Latinoamericana de Ciencias Sociales, FLACSO.

Vélez Vargas, L. D. (2015). Adaptabilidad y persistencia de las formas de producción campesina. Bogotá: Universidad Nacional de Colombia.

Wolf, E. (1971). Los campesinos. Barcelona: Editorial Labor. 